\title{
¿Hacia una nueva institucionalidad cultural? Aportes para un debate en crisis
}

\author{
Belén Sola Pizarro | LAAV, Museo de Arte Contemporáneo de Castilla y León (MUSAC)
}

URL de la contribución <www.iaph.es/revistaph/index.php/revistaph/article/view/4760>

Llevamos años hablando de una supuesta nueva institucionalidad en los museos y esforzándonos trabajadores culturales de toda índole por transformar el concepto de museo heredado de la llustración para convertir estos centros en espacios de democracia cultural y acción social. ¿Qué ha pasado pues para que los esfuerzos de tantos gestores, artistas, mediadores y educadores hayan sido fagocitados de nuevo por la gran empresa del capital y sus estrategias neoliberales de mercado?

En los más de quince años de mi trabajo en el Museo de Arte Contemporáneo de Castilla y León (MUSAC), he sido testigo de dos hechos que tienen que ver, por un lado, con la gestión de los museos y centros de arte, en su mayoría dependientes de fundaciones o instituciones publicas y, por lo tanto, sin ninguna libertad para decidir autónomamente la forma de contratación de su personal o incluso su propia estructura; y, por otro, con la formación muchas veces limitada a la práctica curatorial de los puestos directivos, que a día de hoy son los que siguen ostentando el poder programático y funcional de estos centros.

He sido testigo de que tener un presupuesto holgado no es sinónimo de tener poder para realizar cambios estructurales, y que sigue siendo más importante "llenar" las salas expositivas y programar actividades paralelas con ellas, que pensar estrategias de cambio estructural para el museo, destinando el presupuesto a la activación social del museo y la búsqueda de alianzas múltiples con la ciudadanía.

Desde el departamento de educación y acción cultural del MUSAC, estos últimos puntos han sido el objetivo principal del trabajo, pese a que lo llevamos a cabo desde un lugar descentrado, subalterno, y silencioso, a menudo invisible para el gran público, pero lleno de sen-

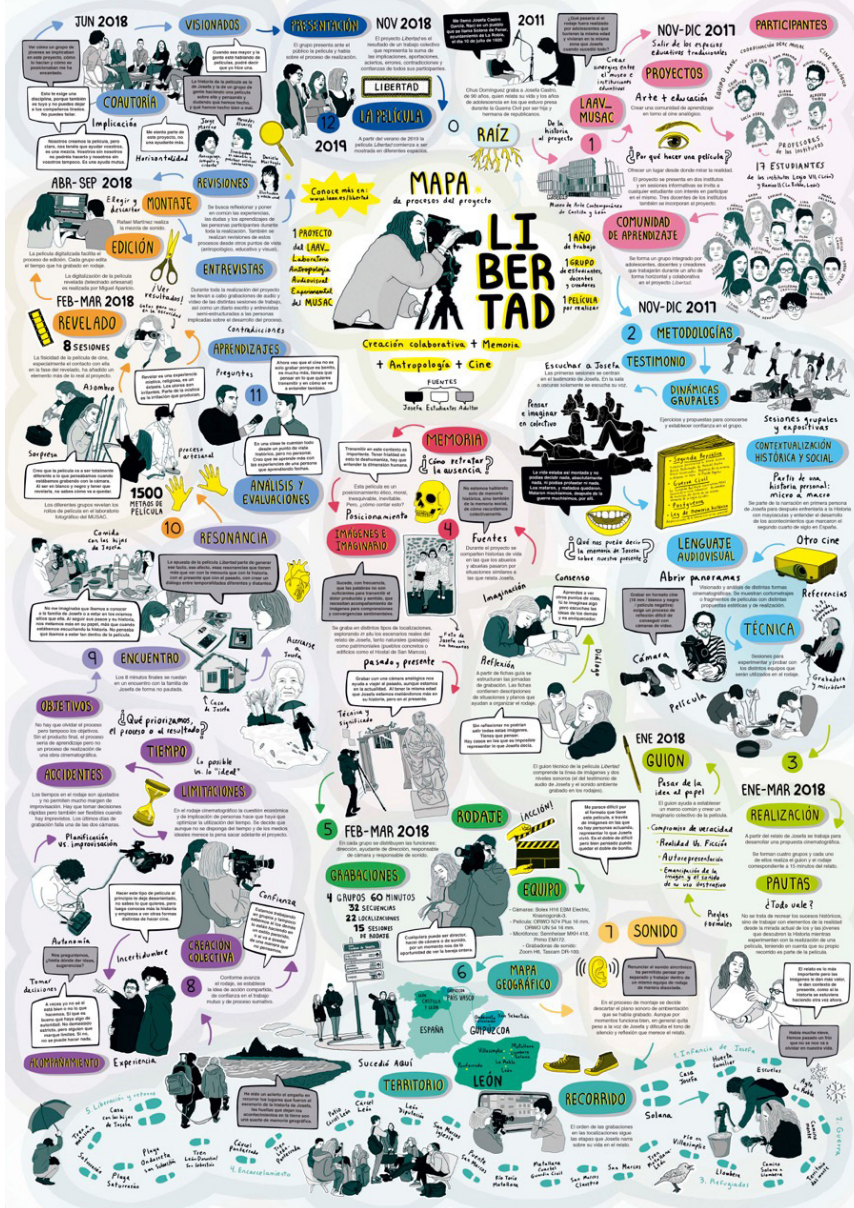

Ilustración del proyecto "Libertad" | Daniela Martagón. Laav_2019

tido para las personas (profesionales del museo y ciudadanía) que hemos trabajado en este proyecto.

Nuestra estrategia ha fluido por un camino lento que buscaba la erosión de la institución a partir de alianzas insospechadas con espacios y agentes independientes y colaboraciones a largo plazo con colectivos ciudadanos. 
a debate Hacia una nueva institucionalidad cultural. Modelos emergentes de gestión...

| coordina Jesús Carrillo Castillo



La humana perfecta (13 min. 2018) | La rara troupe. Still

La paradoja final es que la erosión que esperábamos conseguir en la institución se convirtió en erosión de nuestras propias vidas: la sobre explotación en el trabajo, la incapacidad de detener situaciones de precariedad laboral en nuestras compañeras y, por último, la impotencia de ser testigos de la fragilidad de nuestros proyectos y lo fácil que es para la institución dejarlos caer sin apenas inmutarse.

Esta situación en la que nos hallamos a día de hoy es lo que me mantiene escéptica ante la promesa de la nueva institucionalidad en la que tanto hemos trabajado y me hace dudar de mis palabras en el 2010: ¿sigue siendo el museo un lugar posible? (SOLA PIZARRO, 2010: 23) ${ }^{1}$.

Me planteo que tal vez sea el momento de perder el miedo a imaginar un espacio "extitucional" (en nuestro caso esto esta ocurriendo con la experiencia del LAAV_), un espacio expulsado del "confortable" museo por exceso de crecimiento, por dar demasiados frutos y no estar preparados para recogerlos, alimentarnos con ellos y plantar nuevas semillas.

En este debate abierto sobre de qué modos podemos continuar pensando los museos y centros de arte como espacios de conocimiento y producción cultural crítica, quiero aportar cuestiones que, a mi parecer, son claves para la regeneración democrática de estos espacios:

1. Los perfiles que aún entran a gestionar y dirigir museos están formados en un paradigma del siglo XX: el del curador de exposiciones, más que en el de un trabajador cultural posicionado en la sociedad y en los nuevos desafíos de la democracia cultural que esperamos. ¿Sería pensable, por ejemplo, un museo con una estructura rizomática y abierta a la toma de decisiones consensuadas y equilibradas poniendo a las personas en el centro? Es evidente que el modelo de gobernanza 
a debate Hacia una nueva institucionalidad cultural. Modelos emergentes de gestión...

| coordina Jesús Carrillo Castillo

está en crisis, pero también que son pocos los perfiles que están preparados para ocupar un lugar que, en mi opinión, tiene que ver más con los cuidados (en sentido extenso), la atención y la escucha, que con la generación incesante de propuestas para que las demás personas las materialicen.

2. Es urgente dotar a los centros de capacidad jurídica propia; poder decidir los modelos de contratación y establecer protocolos adecuados que permitan velar por la transparencia de sus gestiones, lo que de nuevo pasa por tener los equipos humanos adecuados y actualizados para tales fines.

3. Es impensable un museo que se proponga tales retos de trabajo con la ciudadanía sin tener los equipos de mediadores-educadores adecuados. Seguirá siendo un trabajo en balde siempre que se entienda la mediación como un servicio al público y no como una función estructural e intrínseca al museo que le permita absorber aprendizajes y regenerar sus funciones de manera crítica con la propia institución, algo que apenas observamos en los museos actuales.

4. Sería interesante continuar el trabajo de recopilación y estudio ${ }^{2}$ de diversas propuestas que se han llevado a cabo en los últimos años en el estado español. Dibujar un mapa de tales prácticas que han perseguido maneras alternativas de funcionamiento de la institución y evaluar las experiencias con sus logros y sus dificultades podría ser una interesante manera de dibujar el presente y futuro de la institución por venir.

\section{NOTAS}

1. En el libro Experiencias de aprendizaje con el arte actual en las políticas de la diversidad utilizaba este subtitulo: El museo, lugar posible, subrayando la necesidad de transformar estos espacios como "emplazamientos simbólicos" de una cultura que ya no nos representa como sociedad a "lugares significativos" de aprendizaje y producción cultural colaborativa que inauguren una nueva manera de pensar la cultura en sociedad.

2. Tenemos bastante bibliografía publicada y otros recursos de investigación a este respecto, que nos permiten poder estudiar cierta genealogía disidente al modelo moderno de museo ensayados en las ultimas dos décadas. Abundante sobre todo -aunque no únicamentedesde las prácticas de mediación y educación. Podemos nombrar, por ejemplo, el archivo de Transductores o las publicaciones del equipo de educación del CA2M (2016) o del DEAC del MUSAC $(2010,2019)$, entre otros.

\section{BIBLIOGRAFÍA}

- SOlA PIZARRO, B. (coord.) (2010) Experiencias de aprendizaje con el arte actual en las políticas de la diversidad. Barcelona: ACTAR; León: MUSAC, 2010

- SOlA PIZARRO, B. (ed.) (2019) Exponer o exponerse, le educación en museos como producción cultural crítica. Madrid: Catarata, 2019 